\title{
Condensed Tannins: Base-Catalysed Reactions of Polymeric Procyanidins with Toluene-a-thiol. Lability of the Interflavanoid Bond and Pyran Ring.
}

\author{
Peter E. Laks" $\uparrow$ and Richard W. Hemingway \\ Southern Forest Experiment Station. USDA-Forest Service, 2500 Shreveport Highway, Pineville. LA 71360
}

\begin{abstract}
Reaction of polymeric procyanidins (condensed tannins) with toluene- $\alpha$-thiol at pH 12.0 and $23^{\circ} \mathrm{C}$ gave predominantly one stereoisomer of 1,3-bisbenzylthio-1-(3,4-dihydroxyphenyl)-3-(2,4,6-trihydroxyphenyl) propan-2-ol (10) by stereoselective reaction at C-4 and C- 2 of the quinone methide derived from the upper 2.3-cis procyanidin units. Smaller amounts of two isomers of 1-benzylthio-1-(3,4dihydroxyphenyl)-3-(2,4,6-trihydroxyphenyl)propan-2-ol (4) were obtained by reaction at the C-2 of catechin obtained from the terminal units. At higher temperatures, (10) loses toluene- $x$-thiol preferentially from $C-1$ to give 1-benzylthio-1-(3,4-dihydroxyphenyl)-3-(2,4,6-trihydroxyphenyl)propan-2-one (11) by a tautomeric rearrangement of the quinone methide via an enol to the ketone. Loss of toluene-x-thiol from (4) gave 1-(3,4-dihydroxyphenyl)-3-(2,4,6-trihydroxyphenyl)propan-2-one (5) by a similar rearrangement. This compound further rearranges to 1-(3,4-dihydroxyphenyl)-4,6dihydroxyindan-2-one (6).
\end{abstract}

Condensed tannins are often extracted and/or allowed to react at alkaline $\mathrm{pH}$ in the course of manufacture of specialty polymers such as tannin-based adhesives. With the exception of some reactions of monomeric flavan-3-ols, ${ }^{1-4}$ and a few flavan derivatives with good leaving groups at $\mathrm{C}-4,{ }^{3.6}$ little work has been published on the base-catalysed reactions of these compounds. When (t)-catechin (2) is dissolved in alkaline solu. tions under comparatively mild conditions (i.e. $\mathrm{pH} 10.5$ and ambient temperature), cleavage within the pyran ring gives a quinone methide (3) that recondenses with the phloroglucinol hydroxy group to give both (t)-catechin (2) and (t)epicatechin (12) in the relative proportions of ca. 3.5 to $1 .^{1-3}$ At higher $\mathrm{pH}$ and/or temperature, the quinone methide [(3) Scheme 1] undergoes intramolecular condensation by nucleophilic attack of the phloroglucinol $A$ ring on the quinone methide with subsequent rearrangement to catechinic acid, an enolic form of 6-(3,4-dihydroxyphenyl)-7-hydroxybicyclo[3.3.1] nonane-2,4,9-trione (13). ${ }^{1,4}$ Similar intramolecular condensations and rearrangements have been proposed in the reactions of condensed tannins in alkaline solution, but no evidence, other than observations of a reduction of phloroglucinol functionality in reactions with aldehydes and appearance of strong carbonyl absorption in the i.r. region. ' has been offered for this conclusion.

In contrast to the reaction of favan-3-ol (i.e. $(+)$-catechin], derivatives with good leaving groups at C.4 (i.e. thio (14) or hydroxy (15) finctions] at $\mathrm{pH} 9.0$ and ambient temperature givi: the quinone methides (16) or (17) without cleavage of the pyran ring." This reaction has been used for the synthesis of epicatechin- $(4 \beta \rightarrow 8)$-catechin, epicatechin-( $4 \beta \rightarrow 6)$-epicatechin, and the 'branched' trimer epicatechin $(4 \beta \rightarrow 8)$-catechin- $(6 \rightarrow 4 \beta)$. epicatechin. ${ }^{3.6}$ These results prompted questions about the reactions of polymeric procyanidins in solutions at higher $\mathrm{pH}$ particularly, as to the relative labilities of the interflavanoid bond and the ether linkage in the pyran ring.

The polymers studied were obtained from the bark of loblolly pine trees (Pinus taeda L.). ${ }^{8}$ Oligomeric procyanidins isolated from the bark [the dimers epicatechin- $(4 \beta \rightarrow 8)$-catechin (1), epicatechin- $(4 \beta \rightarrow 6)$-catechin and small amounts of catechin$(4 x \rightarrow 8)$-catechin' as well as the trimers epicatechin $-(4 \beta \rightarrow 8)$ -

+ Current Address: Institute of Wood Research, Michigan Technological University, Houghton. MI 49931 epicatechin- $(4 \beta \rightarrow 8)$-catechin, epicatechin- $(4 \beta \rightarrow 6)$-epicatechin$(4 \beta \rightarrow 8)$-catechin, and epicatechin- $(4 \beta \rightarrow 8)$-epicatechin$(4 \beta \rightarrow 6)$-catechin ${ }^{10}$ ] reflect the structure of the higher polymers as revealed by ${ }^{13} \mathrm{C}$ n.m.r. ${ }^{8.11 .12}$ and thiolytic degradation products. ${ }^{8-10}$ The $(4 \beta \rightarrow 6)$ and $(4 \beta \rightarrow 8)$ interflavanoid bonds are present in the relative proportions of ca. 3 to 1 , respectively. These tannins have a number average molecular weight of 2500 to 3000 (ca. 9 flavanoid units) and dispersivity ranging from 2 to $4^{8.13}$ To simplify Scheme 1, the polymers are represented by the dimer (1).

Reaction of loblolly pine bark tannins with toluene-x-thiol at pH 12.0 and ambient temperature for 16 or $48 \mathrm{~h}$ produced a series of diarylpropan-2-ol derivatives (Scheme 1). One of the compounds isolated was 1-benzylthio-1-(3,4-dihydroxyphenyl)-3-(2,4,6-trihydroxyphenyl)propan-2-ol (4). Fast atom bombardment mass spectroscopy (f.a.b.-m.s.) of (4) showed an $M+1$ signal of 415 in the positive ion spectrum, in agreement with the calculated molecular weight of $414 .{ }^{13} \mathrm{C}$ N.m.r. spectrometry indicated that this compound was a mixture of two stereoisomers in a ratio of ca. 2:3 (isomeric at the $C-1$ of the propyl function). The chemical shifts of the carbon atoms in the two isomers are similar, with the largest difference of $0.9 \mathrm{~Hz}$ for the asymmetric C-1. The differences in the chemical shift of analogous carbon atoms in the two isomers decrease with distance from the asymmetric centre. The ${ }^{13} \mathrm{C}$ n.m.r. spectrum of the major isomer showed equivalent phloroglucinol tertiary carbons at a chemical shift of 96.8 , the propyl C-3 at 30.4 , the propyl alcohol at 76.9, and the disubstituted, asymmetric $C-1$ at \$6.9 p.p.m. The presence of one benzyithio group on each isomer was evident from the $\mathrm{PhCH}_{2} \mathrm{~S}$ signals at 36.8 and 36.6 p.p.m. ${ }^{12}$ The same isomers in a similar ratio were obtained from the reaction of (+)-catechin with toluene-x-thiol at pH 12.0 and ambient temperature.

The ' $\mathrm{H}$ n.m.r. spectrum of $(4)$ in $\mathrm{CDCl}_{3}-\left(\mathrm{CD}_{3}\right)_{2} \mathrm{CO}$ was complex owing both to the presence of two stereoisomers and the asymmetry of the molecule which made the gem protons at $\mathrm{C} \cdot 3$ and $\mathrm{PhCH}_{2} \mathrm{~S}$ non-equivalent. The gem protons on these carbons have coupling constants of 15 and $13.5 \mathrm{~Hz}$. The presence of two stereoisomers was evident from a doubling of some proton signals with consistently different signal intensities. A signal at $\delta 7.2(\mathrm{~s}, \mathrm{br})$ arose from the phenyl protons of the two isomers. while the signals from the pyrocatechol rings overlapped to give a complex set of signals in the range 6.5-7.0. The 


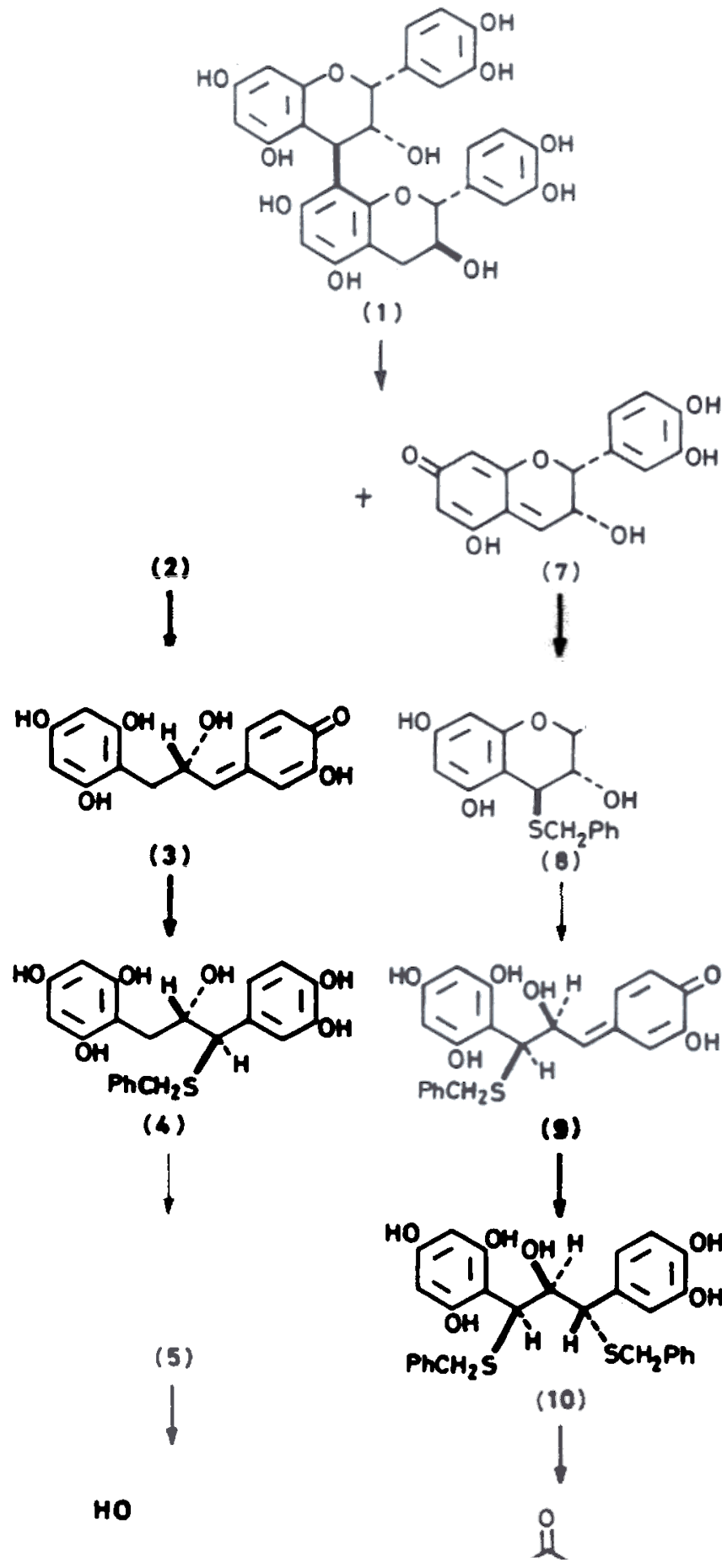

protons on the hydroxylated C-2 positions of the two isomers were also unresolved and gave a complex multiplet centred at $\delta$ 4.0. The major isomer gave a sharp singlet at 85.95 due to the two equivalent protons on the phloroglucinol ring, a doublet at $\delta 3.69$ (J $8 \mathrm{~Hz}, 3-\mathrm{H})$, and two quadruplets centred at 2.92 and $2.56\left(J_{A}=2.5,6.5 \mathrm{~Hz}, 2 \times 1-\mathrm{H}\right)$. The minor isomer resulted in a similar set of signals at $\delta 6.0,3.65(J 7 \mathrm{~Hz}), 3.14(J 2 \mathrm{~Hz})$, and 2.46 ( $J 7.5 \mathrm{~Hz}$ ). In both cases, the gem coupling constant of the<smiles>Oc1ccc([C@@H]2Oc3cc(O)ccc3C[C@H]2O)c(O)c1</smiles>

(12)<smiles>O=C1C=CC2C(O)CC(O)CC2C1c1cccc(O)c1</smiles>

(13)<smiles>Oc1ccc(CC(O)Cc2ccccc2)c(O)c1</smiles>

(18) protons on C-3 was $15.0 \mathrm{~Hz}$ The signals due to $\mathrm{PhCH}_{2} \mathrm{~S}$ in the two isomers had the same chemical shift which resulted in a single double doublet with signals at 3.61 and 3.46 , and a coupling constant of $13.5 \mathrm{~Hz}$. The inner signals were much more intense than the outer ones owing to the small difference in chemical shift and large coupling constant. The measured ratios of outer to inner line intensities is 0.074 which agrees well with the calculated, theoretical value of 0.071 .

The formation of two stereoisomers in nonequivalent amounts is consistent with the intermediate of this reaction being a quinone methide in an extended conformation as shown by structure (3). Previous work on the reactions of flavan derivatives with good leaving groups at $\mathrm{C}-4$ indicated facile formation of quinone methide intermediates under mild alkaline conditions ${ }^{5.6}$ a conclusion supported by the spectral studies of Attwood et al. ${ }^{14}$ Analogous formation of a quinone methide (3) in cleavage of the pyran ring is clearly consistent with the rapid epimerization of flavan-3-ols in mild alkaline solutions. ${ }^{1.2}$ In this case, nucleophilic atteck by the toluene-zthiol would occur preferentially at the least hindered side, away from the C.2 hydroxy group, and implying that the isomer occurring in higher concentration is the $1 R$ isomer as shown in structure (4).

Reaction of (4) with Raney nickel gave 1-(3,4-dihydroxyphenyl)-3-(2,4,6-trihydroxyphenyl)propan-2-ol (18). This compound has been reported previously, but without a complete description of its n.m.r. spectra. ${ }^{15}$ The ${ }^{13} \mathrm{C}$ n.m.r. spectrum showed the signal due to the symmetrical phloroglucinol carbons at 96.9, the propyl C-3 at 31.6, the hydroxylated C-2 at 75.8, and the C-1 methylene at 44..2 p.p.m. Apart from the latter signal and absence of a phenylmethane group, this spectrum was very similar to that of the previous compound discussed (4).

The ${ }^{i} \mathbf{H}$ n.m.r. of this compound was again quite complex 
<smiles>Oc1ccc(C(O)C(SCc2ccccc2)C(O)Cc2ccccc2)c(O)c1</smiles>

(4)

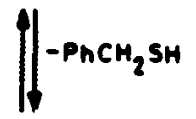<smiles>O=C1C=CC(=CC(Cc2ccccc2)C(O)Cc2ccccc2)C=C1O</smiles><smiles>OC(=Cc1ccc(O)cc1)Cc1cc(O)cc(O)c1</smiles>

(19)

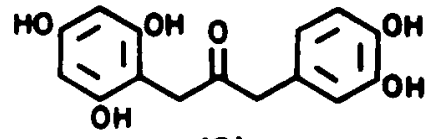

(5)

Schen 2. Elimination and tautomerisation of the catechin-toluene-athiol adduct 10 a propanone derivative

owing to the asymmetric nature of C-2 which made the gem protons on $\mathrm{C}-1$ and $\mathrm{C}-3$ non-equivalent. The spectrum has essentially four sets of signals-a multiplet at 6.7 due to the tertiary protons on the pyrocatechol ring, a sharp singlet at $\delta$ 5.95 from the phloroglucinol tertiary hydrogens, a multiplet at $\delta$ 4.05 for the proton on C-2, and a complex set of signals centred on $\delta 2.75$ due to the protons on C-1 and C-3. The signal at 4.05 can be interpreted as a single proton being split by four adjacent, non-equivalent hydrogens with coupling constants of 2.5. 4.5, 5.0, and $9.0 \mathrm{~Hz}$ The multiplet at 2.75 can be interpreted as four overlapping double-doublets centred at chemical shifts of $2.57(J 8,14 \mathrm{~Hz}), 2.67(J \mathrm{~S}, 9 \mathrm{~Hz}), 2.83(J \mathrm{~S}, 9 \mathrm{~Hz})$, and $2.99(J 3$, $14 \mathrm{~Hz}$ ).

A second product isolated from the reaction of loblolly pine bark tannins with toluene-a-thiol at pH 12.0 and $23^{\circ} \mathrm{C}$ for $16 \mathrm{~h}$. was the 1,3-bisbenzylthio derivative (10). High resolution f.a.b.-m.s. showed $M+1=537.1393$, in agreement with the calculated value for $\mathrm{C}_{29} \mathrm{H}_{28} \mathrm{O}_{6} \mathrm{~S}_{2}+1$ of 537.1406. Several isomers of this compound were evident from the multiplicity of signals in the ${ }^{13} \mathrm{C}$ n.m.r. spectrum. However, in contrast to the formation of (4), one isomer was preferentially produced in a relative yield of $\mathrm{ca}$. $90 \%$ of the product. The major isomer was isolated by column chromatography. Substitution at both $\mathrm{C}-1$ and $\mathrm{C} .3$ of the propyl function was evident from resonance; at $\delta$ 48.6 and 55.0 p.p.m., respectively, with the propyl C.-2 at $\delta 79.2$ p.p.m. Equivalent phloroglucinol tertiary carbons appeared at $\delta$ 96.7 p.p.m. PhCH $\mathrm{H}_{2} \mathrm{~S}$ signals at $\delta 36.4$ and 37.3 p.p.m. were consistent with the presence of two benzylthio groups. Reduction of (10) with Raney nickel also gave a stereoisomer of the diarylpropanol, (18).

In acetone solution, the ' $H$ n.m.r. spectrum showed a complex multiplet at $\delta 7.1$ due to the phenyl ringer a further multiplet in the range $6.8-6.2$ for the pyrocatechol ring protons, a sharp singlet at 5.9 from the phloroglucinol ring. a $H$ doublet at $4.65(J 4 \mathrm{~Hz})$, a $1 \mathrm{H}$ double doublet at $4.4(J 4,9$ $\mathrm{Hz}$ ), a further doublet at $\delta 3.6(J 9 \mathrm{~Hz})$, a $2 \mathrm{H}$ double doublet resulting from two mutual splitting of the gem hydrogens at $\delta 3.65$ and $3.38(J \mid 1.5 \mathrm{~Hz})$, and a $2 \mathrm{H}$ singlet at $\delta 3.52$.

The stereoselective formation of predominantly one isomer implies that interflavanoid bond cleavage occurs first, followed by opening of the pyran ring. In acid-catalysed cleavage of 2.3 . cis-procyanidins, thiol addition proceeds through the quinone methide intermediate (7), giving the 3.4-trans isomer (8) exclusively. Although (8) was not isolated from the alkaline reactions of procyanidins with toluene-a-thiol, the equivalent adduct was observed in similar reactions with phloroglucinol as the nucleophile. ${ }^{16}$ This implies a is configuration for (10). When the pyran ring opens to form the quinone methide intermediate (9), the 1-benzylthio group and the 2-hydroxy become cis. The bulky 1-benzylthio group in (10) makes trans addition to C.3 more predominant than in the formation of (4). On the basis of the mechanism, the major product should be $1 S, 3 S$ as shown in structure (10).

Since the 1-benzylthio substituent ( $\alpha$ to the phloroglucinol ring) would be expected to be a good leaving group, the stereochemistry of the final products should reflect thermodynamic rather than kinetic control; in contrast the 3-benzylthio substituent would not be expected to be a good leaving group. ${ }^{17.18}$ Dreiding models show that substitution at C-1 after loss of toluene-a-thiol from (10) can be expected to be stereoselective, predominantly cis to the aliphatic hydroxy group and trans to the 3-benzylthio substituent on the basis of less steric hindrance. The stereochemistry of $(10)$ as shown in Scheme 1 is, therefore, consistent with that expected from thermodynamic control.

The products (4) and (10) are unstable in alkaline solution and after $48 \mathrm{~h}$ at $23^{\circ} \mathrm{C}$ or $12 \mathrm{~h}$ at $100^{\circ} \mathrm{C}$, three products were isolated that initially gave a red colour fading to an intense purple or blue, when sprayed with vanillin- $\mathrm{HCl}$ on cellulose t.l.c. plates. Separations on Sephadex LH-20 gave pure isolates of these compounds. One was identified as 1-(3,4-dihydroxyphenyl)-3-(2,4,6-trihydroxyphenyl)propan-2-one (5). The calculated molecular weight of 290 was confirmed by a positive-ion f.m.b.-m.s. showing a very strong $M+1$ signal at 291 . The presence of a carbonyl group was confirmed by f.t.-i.r. spectroscopy which showed a strong absorbance at $1732 \mathrm{~cm}^{-1}$ and by ${ }^{13} \mathrm{C}$ n.m.r. spectroscopy where a signal at $\delta 212.1$ p.p.m. was observed. Equivalent tertiary phloroglucinol carbons were observed at a chemical shift of 96.3 p.p.m. while the propyl C-3 and C-1 were apparent at 38.1 and 48.7 p.p.m. The rest of the carbon spectrum showed typical pyrocatechol $B$ ring and quaternary phloroglucinol a ring absorbances.

The ' $\mathbf{H}$ n.m.r. of this compound was comparatively simple. showing the pyrocatechol ring absorbances in the range 6.36.8, a sharp singlet for the phloroglucinol ring protons at 6.0 , and two, $2 \mathrm{H}$ singlets at 3.60 and 3.64 p.p.m. The latter signals were assigned to the methylene groups on either side of the carbonyl.

The second compound that gave a purple reaction with vanillin- $\mathrm{HCl}$ is a benzylthio derivative of the previously discussed compound (11). The ${ }^{13} \mathrm{C}$ n.m.r. spectrum was similar to that of (5) except for the addition of absorbances due to a benzylthio function at $\delta 36.2$ and ca. 130 p.p.m., and shift of the signal from the propane carbon a to pyrocatechol to $\delta 58.2$. The positive ion f.a.b. - m.s. showed a clear $M+1$ signal at 413 . 
' $\mathrm{H}$ n.m.r. group.r. spectrum of (11) was again quite simple. The phenyl being resulted in a singlet at $\delta 7.2$, the pyrocatechol ring signals protons gave a in the range 6.5-7.0, the phloroglucinol singlet at 5.95 , a $1 \mathrm{H}$ singlet at $\delta 4.75$ was 3.55 p.p.m., respectiv and $\mathrm{PhCH} \mathrm{H}_{2} \mathrm{~S}$ gave $2 \mathrm{H}$ singlets at 3.65 and

ctively.

The third compound isolated from the extended reaction of tannins with alkaline toluene- $x$-thiol gave a light blue colour with vanillin- $\mathrm{HCl}$, in contrast to the dark purple of the last described two compounds. This compound was identified as 1 i.r. spectrum showed -4,6-dihydroxyindan-2-one (6). An f.t.while the ${ }^{13} \mathrm{C}[(\mathrm{CD})$ carbonyl ${ }^{2}\left[\left(\mathrm{CD}_{3}\right)_{2} \mathrm{SO}\right]$ n.m.r. spectrum had a typical the the carbon spectrum were the two hydroxylated quaternary carbons at carbons at $\delta 157.8$ and 154.2 , the tertiary resorcinol cyclopentane $\delta 103.1$ and 101.6, the tertiary $C-1$ of the F.a.b-mentane ring at $\delta 58.8$, and 3-methylene at $\delta 40.6$ p.p.m. positive in the compound was done in both the positive ion and negative ion modes. The former showed 271 . Both result 273 , while the latter showed a $M-1$ signal at 272. High-results agree with the calculated molecular weight of of 273.0765, in clion f.a.b.-m.s. indicated a molecular weight 273.0763.

The ${ }^{1} \mathrm{H}$

pyrocatechol ringectrum of (6) showed absorption typical of resorcinol ring at 6.1 and singlet at 4.37 at $\delta 6.1$ and $6.35(J 2 \mathrm{~Hz}), 1 \cdot \mathrm{H}$ produced a $1 \mathrm{H}$ conclusions could be $3-\mathrm{CH}_{2}$ gave a $2 \mathrm{H}$ singlet at $\delta 3.38$. No C-1 from this data.

this data.

The reactions of polymeric procyanidins with toluene- $\alpha$-thiol at $\mathrm{pH} 12.0$ and ambient temperature are summarized in Scheme 1. Both the interflavanoid bond and the heterocyclic ring undergo ready cleavage with the formation of quinone methides which react with the nucleophilic thiol to produce benzylthio derivatives of diarylpropanoids. Catechin cleaved from the terminal unit forms two 1-benzylthio isomers (4) from attack on the heterocyclic ring. Formation of predominantly one stereoisomer of (10) from the 2,3-cis chain extender units would restrict interflavanoid bond cleavage occurs first. This hydroxy group, astitution at $\mathrm{C}-4$ to one isomer, trans to the 3 procyanidins, as occurs in acid-catalysed reactions of 2,3-cis phloroglucinol thiols. Small amounts of epicatechin-(4B)phloroglucinol were isolated from a similar alkaline reaction of derivative (10) phloroglucinol. ${ }^{16}$ The equivalent benzylthio substitution the pyran ring is quinone methide produced from cleavage of

tereoselective.

Much larger amounts of (10) were obtained from reactions for $16 \mathrm{~h}$ than for $48 \mathrm{~h}$ at $23^{\circ} \mathrm{C}$. Low yields of (10) were obtained from reactions at $100^{\circ} \mathrm{C}$ for $12 \mathrm{~h}$. The highest yields of $(10)$ were was equivalent the most mild reaction conditions studied and form equivalent to $\mathrm{ca}$. $25 \%$ molar yield per $\mathrm{C}_{15}$ unit. The rapid interflion of (10) at ambient temperature indicates that the than in acetic acid solutions ${ }^{19}$ labile to cleavage at $\mathrm{pH} 12.0$

The propanone compounds (5) and (11) can be formed from quinone methide intermediates by tautomeric shifts of protons. The diarylpropanone (5) is formed by a tautomeric shift of the which methide [(3), Scheme 2] to form initially an enol (19) which then rearranges to the ketone (5). The formation of (11) adduct 4 10)ed in a similar manner from the bisbenzylthio phlo phloroglucinol ring. The fact that the concentration of these disappear, infers that these reactions are in equilibria as shown.
Table 1. Selected ${ }^{13} \mathrm{C}$ n.m.r. chemical shifts for diarylpropane derivatives from reaction of condensed tannins with toluene- $x$-thiol at $\mathrm{pH} 12.0$

\begin{tabular}{|c|c|c|c|c|c|}
\hline \multirow[b]{3}{*}{ Compd. } & \multicolumn{5}{|c|}{ Carbon number } \\
\hline & \multicolumn{3}{|c|}{ Propane } & \multicolumn{2}{|c|}{ A-Ring } \\
\hline & 3 & 2 & $i$ & 3 & 5 \\
\hline$(4)^{a}$ & 56.9 & 76.9 & 30.4 & 96.8 & 96.8 \\
\hline$(10)^{a . b}$ & 55.0 & 79.2 & 48.6 & 96.7 & 96.7 \\
\hline$(18)^{a . b}$ & 44.2 & 75.8 & 31.6 & 96.9 & 96.9 \\
\hline$(5)^{a}$ & 48.7 & 212.1 & 38.1 & 96.3 & 96.3 \\
\hline$(11)^{c}$ & 58.2 & 206.0 & 36.4 & 95.0 & 95.0 \\
\hline$(6)^{r . d}$ & 58.8 & 214.7 & 40.6 & $\begin{array}{l}101.6 \\
(\mathrm{C}-5)\end{array}$ & $\begin{array}{l}103.1 \\
(C .7)\end{array}$ \\
\hline
\end{tabular}

${ }^{a}$ Major isomer. ${ }^{b}$ In $\left[{ }^{2} \mathrm{H}_{6}\right]$ acetone $\delta$ from $\left(\mathrm{CD}_{3}\right)_{2} \mathrm{CO}$ at 30.3 p.p.m. " In $\left[{ }^{2} \mathrm{H}_{4}\right]$ methanol, $\delta$ from $\mathrm{CD}_{3} \mathrm{OD}$ at 49.0 p.p.m. "Tertiary carbon
adjacent to aromatic rings is $\mathrm{C} \cdot 1$.

The first and second steps are slow, while the final ketonization is fast; this stabilizes the final product and forces the previous equilibria to form more intermediates. An analogous tautomeric rearrangement of a quinone methide from loss of the 4-hydroxy group from flavan-3,4-diols provides an explanation for the biogenesis of 2,3-cis-procyanidins from $2 R, 3 R$ dihydroflavonols. ${ }^{20}$

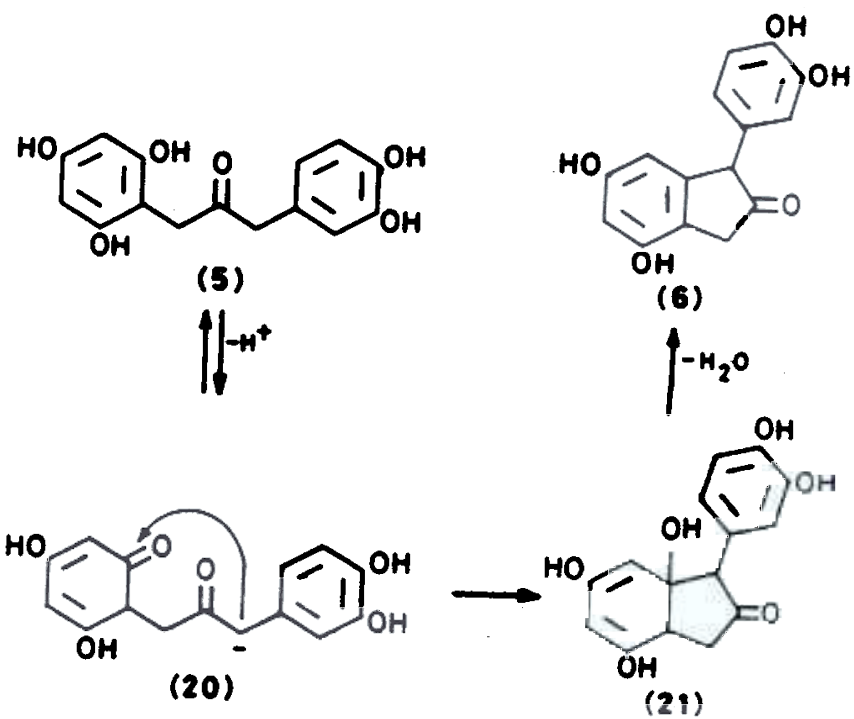

Scheme 3. Rearrangement of 1-(2,4,6-trihydroxyphenyl)-3-(3,4-dihy droxyphenyl)propanone to an indan derivative

The indan derivative (6) it is believed is formed from (5) by rearrangement and dehydration, as outlined in Scheme 3. A carbanion formed from loss of a proton from C-1 attacks the carbonyl carbon of a non-aromatic tautomer of the phloroglucinol ring (20) to form a tertiary alcohol intermediate (21) which dehydrates to form the final product.

\section{Experimental}

'H N.m.r. spectra were recorded at $80 \mathrm{MHz}$ and ${ }^{13} \mathrm{C}$ n.m.r. at $20 \mathrm{MHz}$ with a Varian FT-80A spectrometer. Assignments of ${ }^{13} \mathrm{C}$ n.m.r. resonances were based on data provided in

Mention of trade names does not constitute endorsement by the
USDA-Forest Service. 
Porter ef al., ${ }^{12}$ the chemical shifts of methylene carbons of variously substituted bis-hydroxyphenylmethanes, comparisons among the chemical shifts found for the products, and, in certain instances, on results obtained from proton coupled spectra. $\left[{ }^{2} \mathrm{H}_{6}\right]$ Acetone was used as the solvent, unless otherwise specified. F.t.-i.r. spectra were provided by Dr. T. P. Schultz. Mississippi State University, Mississippi. Mass spectral determinations were performed by the Midwest Center for Mass Spectrometry, a National Science Foundation Regional Instrumentation Facility (Grant No. CHE 8211164). Elemental analyses were performed by Galbraith laboratories.

Separations by column chromatography were done with Sephadex LH-20 packing material using $95 \%$ ethanol as the eluting solvent, unless indicated otherwise. Cellulose t.l.c. analyses were performed on Schleicher and Schull F1440 sheets in the following solvent systems; A, t-butyl alcohol-acetic acidwater $(3: 1: 1, v / v) ; B, 6 \%$ acetic acid in water $(v / v)$. Deoxygenated water was prepared by freezing distilled water (300 ml), placing the resulting ioe under vacuum for $5 \mathrm{~min}$. flushing with nitrogen, and then allowing the ice to melt. The alternating freezing and thawing were repeated twice. The resulting degassed water was stored under a nitrogen atmosphere. Evaporations were done using a rotary evaporator with a water-bath set at $32^{\circ} \mathrm{C}$. Acetylations were done with acetic anhydride-pyridine $(1: 1)$ at room temperature overnight.

Exiraction of Loblolly Pine Phloem-Bark collected from a loblolly pine tree [Pinus taeda, 10 in DBH (Diameter at Breast Height)] was steeped in acetone-water $(7: 3, v / v)$ for $72 \mathrm{~h}$. The extract was then concentrated and freeze-dried to give a redbrown solid. A portion of this crude extract $(50 \mathrm{~g})$ was diseolved in methanot-water $(1: 1, v / v ; c a .100 \mathrm{ml})$ and applied to a Sephadex LH-20 column $(2.5 \times 70 \mathrm{~cm})$ which was eluated with the same solvent for $16 \mathrm{~h}$. The column was then eluted with acetone-water $(1: 1)$, v/v) until the eluant was no longer coloured. Evaporation and freeze-drying of the acetone-water solution gave a light brown solid. "' C N.m.r. analysis of this material showed it to be relatively pure, higher-molecular weight procyanidins with little or no carbohydrate content.

Alkaline Reaction of Procyanidins with Tolmene-a-thiol at $23^{\circ} \mathrm{C}$ for $18 \mathrm{~h}$.- Purified loblolly pine tannin ( $\left.5.0 \mathrm{~g}\right)$ was combined with toluene- $x$-thiol $(10 \mathrm{~g})$ and deoxygenated water $(75 \mathrm{ml})$. The $\mathrm{pH}$ was then adjusted to 12.0 by adding solid sodium hydroxide with constant magnetic stirring. During the sodium hydroxide addition, the surface of the solution was continually flushed with $\mathrm{N}_{2}$. The resulting dart red solution was sealed in a reaction vial $(100 \mathrm{ml})$ under an $\mathrm{N}_{2}$ atmosphere and kept at $23^{\circ} \mathrm{C}$ in a thermostatically controlled water-bath for $18 \mathrm{~h}$

After neutralization with dilute $\mathbf{H C l}$, again under an $\mathbf{N}_{2}$ blanket, the solution was evaporated to give a viscous, redpurple material and a colourless liquid. The unchanged toluene$x$-thiol was removed by stirring the mixture with hexane $(100$ $\mathrm{ml}$ ) for $10 \mathrm{~min}$ and then removing the hexane layer. This trituration was repeated twice further and the hexane layers discarded. The resulting product was dissolved in water along with a minimum of ethanol and then freeze-dried. The crude product was applied to a Sephadex LH-20 column $(2.5 \times 75$ $\mathrm{cm})$. packed and eluted with $95 \%$ ethanol. Tubes 40-75 were combined and evaporated to give a waxy, amorphous solid $(5.14 \mathrm{~g})$. This material was re-applied to a column $(2.5 \times 75$ $\mathrm{cm})$, packed and eluted - with chloroform-ethanol $(4: 1, v / v)$. Fractions 77-95 were combined and evaporated to give a solid $(1.8 \mathrm{~g})$ which was applied to a smaller Sephadex LH-20 column $(1.5 \times 80 \mathrm{~cm})$ eluted with chloroform-ethanol $(1: 1, \mathrm{v} / \mathrm{v})$.

1,3-Bisben:ylthio-1-13,4-dihydroxypheny)-3-12,4,6-trihydroryphenyhpropan-2-ol (10) $(1.23 \mathrm{~g})$ was obtained from fractions 29-36, having $R_{F} 0.48$ (streaks) and 0.72 in solvents $B$ and $A$. giving a red colour with vanillin-HCl [Found: $m / z$ (f.a.b.-m.s.) $M+1,537.1393$. $\mathrm{C}_{29} \mathrm{H}_{20} \mathrm{O}_{6} \mathrm{~S}_{2}$ requires $M+1$. 537.1406]; $\delta 36.4$ and $37.3\left(\mathrm{CH}_{2}\right.$ S), 48.6 (propyl C-3), 55.0 (propyl C-1), 79.2 (propyl C-2), 96.7 (C-3 + C-5, phloroglucinol), 116.1, 116.9, and 121.4 (C-2, C-5, and C-6, pyrocatechol), 107.0 and 134.5 (C-1, phloroglucinol and pyrocatechol) 127.5, 129.1, 129.9, 130.1 (tertiary phenyl), 140 (quaternary phenyl), 145-147 (C-3 + C-4, pyrocatechol), and 157-159 (C-2, C-4, and C-6, phlorogiucinol); $\delta\left[\left(\mathrm{CD}_{3}\right)_{2} \mathrm{CO}\right]$ 3.38 ( I H, d, J11.5 Hz, CH, S), 3.52 ( $2 \mathrm{H}$, s, benzyl CH, $\mathrm{S}$ ), 3.6 (1 $\mathrm{H}, \mathrm{d}, J 9 \mathrm{~Hz}, 3-\mathrm{H}), 3.65$ (1 H, d, J $11.5 \mathrm{~Hz}$ benzyl $\mathrm{CH}_{2} \mathrm{~S}$, $4.4(1$ $\mathrm{H}, \mathrm{dd}, J 4,9 \mathrm{~Hz}, 2-\mathrm{H}$ ), 4.65 (1 H, d, J $4 \mathrm{~Hz}, 1-\mathrm{H}), \mathrm{S.9}$ (2 H, s, phloroglucinol), 6.5 (3 H, m, pyrocatechol), and $7.1(10 \mathrm{H}, \mathrm{m}$. phenyl). Reaction of (10) with Raney Ni gave $1+(3,4$ dihydroxyphenyl)-3-(2,4,6-trihydroxyphenyl)propan-2-ol.

Alkaline Reacrion of Procyanidin with Toluene-z-thiol at $23^{\circ} \mathrm{C}$ for $48 \mathrm{~h}$. - The same procedure described above was used, except the reaction solution was left at $23^{\circ} \mathrm{C}$ for $48 \mathrm{~h}$ before work-up. After diseolution in a minimum of $95 \%$ ethanol, the crude product was applied to a Sephadex LH-20 column $(25 \times 75 \mathrm{~cm})$. packed and eluted with the same solvent. Fractions 27-44 were combined, evaporated, and freeze-dried to give material $(1.13 \mathrm{~g})$ which was re-applied to a small column of LH-20 $(1.5 \times 80 \mathrm{~cm})$ packed and eluted with ethanol-water $(1: 1, v / v)$.

1-(3,4-Dihydroxypheny)-3-(2,4,6-trihydroxypheny)propan-2one (5), (34 mg) was obtained from fractions 39-43, as a light brown amorphous solid. $R_{F} 0.53$ on cellulose t.l.c. plates developed with solvent $B$, initially red, lading to a purple-blue colouration with vanillin-HC (Found: $\mathrm{C}$, 59.05: $\mathrm{H}$. 5.3. $\mathrm{C}_{1}, \mathrm{H}_{1}, \mathrm{O},-0.8 \mathrm{H}_{2} \mathrm{O}$ requires $\mathrm{C}, 59.13 ; \mathrm{H}, 5.12 \%$ ) [Found: $\mathrm{m} / \mathrm{z}$ (fab.-ms.) $M+1,291$. $\mathrm{C}_{1}, \mathrm{H}_{14} \mathrm{O}_{6}$ requires $\left.M+1,291\right]$. ${ }^{13} \mathrm{C}$ N.m.r. showed 8: 38.1 (propyl C-3) 48.7 (propyl C-1), 96.3 (C-3 + C-5, phloroglucinol), 101.9 (C-1 phloroglucinol), 116.4, 118.2, 122.5, and 127.8 (C-2, C-5, C-6, and C-1, pyrocatechol). 145.0 and 146.0 (C-3 and C-4, pyrocatechol), 158-159 (C-2. C-4, and C-6, phloroglucinol), and 2121 (propyl C-2 carbonyl). The f.t.-i.r. spectrum showed a C-O at $1732 \mathrm{~cm}^{-1} ; \delta 3.60(2 \mathrm{H}$. 3, propyl 1-H or 3-H), 3.64 (2 H, s, propyl 1-H, or 3-H), 6.0 (2 H. s. phloroelucinol ArH), and $6.6(3 \mathrm{H}, \mathrm{m}$, pyrocatechol ArH).

1-Benzylthio-1 (3,4-dihydroxyphenyl)-3-12,4,6-trihydroxypheny/propan-2-one (11) (131 mg) was obtained from fractions 63-69 as a light brown solid having $R_{F} 0.60$ on cellulose t.l.c. plates in solvent B. giving initially a red, then purple-red colour with vanillin-HCl [Found: $m / z$ (f.a.b.-m.s.) $M+1,413.1056$. $\mathrm{C}_{22} \mathrm{H}_{20} \mathrm{O}_{6} \mathrm{~S}$ requires $\left.M+1,413.1059\right], \delta_{c} 36.4$ and 36.2 (propyl $\mathrm{C}-3$ and benzyl $\mathrm{CH}_{2} \mathrm{~S}$ ), 58.2 (propyl $\mathrm{C}-1$ ), 95.0 (C-3 and C-5, phloroglucinol), 115.8, 116.6, 121.5 (C-2. C-5, and C-6. pyrocatechol), 127.4, 128.9, 129.5 (phenyl tertiary carbons). 145 (C-3 and C-4, pyrocatechol) 157-159 (C-2, C-4, and C-6. phloroglucinol), and 206 (propyl C-2); 83.65 (2 H, s, propyl 3-H or benzyl $\mathrm{CH}_{2} \mathrm{~S}$ ), 3.55 ( $2 \mathrm{H}_{2}$ s, propyl 3-H or benzyl $\left.\mathrm{CH}_{2} \mathrm{~S}\right), 4.75$ (1 H, s, propyl 1-H), 5.95 (2 H, s, phloroducinol ArH), 6.7 (3 H. m. pyrocatechol ArH), and 7.2 (5 H, m, benzyl ArH).

1-Benzylthio-1-(3,4-dihydroxyphenyl)-3-(2,4,6-trihydro.rypheny')propan-2-ol (4) (293 mg) was obtained from fractions $70-94$ as a tan-coloured, amorphous solid with $R_{F} 0.52$ on cellulose t.l.c. plates in solvent B, giving a red colour with vanillin- $\mathrm{HCl}$ (Found: $\mathrm{C}, 61.25 ; \mathrm{H}, 5.9, \mathrm{~S}, 7.5$. $\mathrm{C}_{22} \mathrm{H}_{22} \mathrm{O}_{6} \mathrm{~S}-\mathrm{H}_{2} \mathrm{O}$ requires C, 61.11; H. S.5s; S, 7.41\%) [Found: $m /=$ (f.a.b.-m.s.) $M+1,415 . M+1$ requires 415$]$; $\delta_{c}$ (major isomer) 30.4 (propyl C-3), 36.8 (benzyl CH $\mathrm{C}_{2}$ S), 56.9 (propyl C-1). 76.9 (propyl C-2), 96.8 (C-3 + C.5, phloroducinol), 116.1. 117.4, and 122.7 (C-2, C-5, and C-6, pyrocatechol), 132.3 (C-1, pyrocatechol), 128.1, 129.6, and 130.4 (C-2 + C-6; C-3 + C-5; and C-4. phenyl), 145-147(C-3 + C-4, pyrocatechol) and 156-157(C. 
2. C-4, and C-6, phloroglucinol); $\delta 2.56(1 \mathrm{H}, \mathrm{dd}, J 6.5,15.0 \mathrm{~Hz}$, propyl 3-H), 2.92 ( $1 \mathrm{H}$, dd, $J 2.5,15.0 \mathrm{~Hz}$ propyl 3-H), 3.53 (2 H, dd, $J 13.5 \mathrm{~Hz}$ benzyl $\left.\mathrm{CH}_{2} \mathrm{~S}\right), 3.69(1 \mathrm{H}, \mathrm{d}, J 8 \mathrm{~Hz}$ propyl 1.H), and $4.0(1 \mathrm{H}, \mathrm{m}$, propyl $2-\mathrm{H})$, in addition to expected resonances for phloroglucinol, pyrocatechol, and phenyl ArH protons at $5.95(2 \mathrm{H}, \mathrm{s}), 6.7(3 \mathrm{H}, \mathrm{m})$, and $7.2(5 \mathrm{H}, \mathrm{m})$. The minor isomer had carbon signals at: $\delta 30.0$ (propyl C-3), 36.8 (benzyl $\mathrm{CH}_{2} \mathrm{~S}$ ), 57.8 (propyl C-1), 77.9 (propyl C-2), and 96.9 (C-3 + C.5. phloroglucinol) with multiplicity in the lower field carbons. The ' $H$ n.m.r. spectrum of the minor isomer showed a similar set of signals: $\delta 2.46(1 \mathrm{H}, \mathrm{dd}, J 7.5,15.0 \mathrm{~Hz}), 3.14(1 \mathrm{H}$, dd, $J 2.0,15.0$ Hz), 3.53 ( $2 \mathrm{H}, \mathrm{dd}, J 13.5 \mathrm{~Hz}), 3.65(1 \mathrm{H}, \mathrm{d}, J 7 \mathrm{~Hz}), 4.0(1 \mathrm{H}, \mathrm{m})$, and $6.0(2 \mathrm{H}, \mathrm{s})$. The other aromatic ring signals of the isomers could not be separated. Reaction of (4) with Raney Ni gave 1(3.4-dihydroxyphenyl)-3-(2,4,6-trihydroxyphenyl)propan-2-ol.

Alkaline Reaction of Procyanidins with Toluene-a-thiol at $100{ }^{\circ} \mathrm{C}$ for $12 \mathrm{~h}$.- The procedure described above was used, except for the reaction conditions of $12 \mathrm{~h}$ in an oven set at $100^{\circ} \mathrm{C}$. The crude product was applied to a Sephadex LH-20 column $(2.5 \times 75 \mathrm{~cm})$, eluted with $95 \%$ ethanol. Tubes 135 145 were combined, evaporated, and re-applied to a second column $(2.5 \times 75 \mathrm{~cm})$, again eluted with the same solvent. Fractions $21-23$ gave the propan-2-one (5), physically and spectroscopically identical with that from an earlier preparation. Fractions 103-129 from the first column were also applied to a $2.5 \times 75 \mathrm{~cm}$ Sephadex L.H-20 column, packed and eluted with $95 \%$ ethanol.

$1-(3,4$-Dihydroxypheny) -4,6-dihydroxyindan-2-one (6) was obtained from fractions $21-35(357 \mathrm{mg})$ of the last column above after passing through yet a further LH-20 column of this size to give finally $65 \mathrm{mg}$ of product (fractions $36-40$ ); $R_{F} 0.71$ and 0.73 on cellulose t.l.c. plates in solvents $A$ and $B ;$ [Found: $m / z$ (f.a.b.-m.s.) positive ion, $M+1,273$; negative ion, $M-1$, 271; high-resolution positive ion, $M+1,273.0765 . \mathrm{C}_{1}, \mathrm{H}_{12} \mathrm{O}_{3}$ requires, 273,271 , and 273.0763 respectively $] ; \delta_{c}\left[\left(C_{13}\right)_{2} \mathrm{SO}\right]$ : 40.6 (C-1), 58.8 (C-3), $101.6(\mathrm{C}-6), 103.1(\mathrm{C}-4), 115.5,115.7,119.4$ (C-2, C-5, and C-6, pyrocatechol), 129.8 (C.1, pyrocatechol), $144.2,145.1$ (C-3 and $C-4$, catechol), and 154.2 and $157.8(C-4$ and $\mathrm{C}-6) ; \delta 3.38(2 \mathrm{H}, \mathrm{s}, 3-\mathrm{H}), 4.37(1 \mathrm{H}, \mathrm{s}, 1-\mathrm{H}), 6.1(1 \mathrm{H}, \mathrm{d}, \mathrm{J} 2$ $\mathrm{Hz}, \mathrm{S}-\mathrm{H}), 6.35(1 \mathrm{H}, \mathrm{d}, J 2 \mathrm{~Hz}, 7 . \mathrm{H})$, and $6.5(3 \mathrm{H}, \mathrm{m}$, pyrocatechol ArH).

Catechin with Toluene-a-thiol under Basic Conditions.Toluene-z-thiol $(5.0 \mathrm{ml})$ was combined with $50 \mathrm{ml}$ of water and the pH adjusted to 12 with solid $\mathrm{NaOH}$. Catechin $(2.5 \mathrm{~g})$ was then added to the solution which was subsequently sealed in a reaction vial under an $N_{2}$ atmosphere and left at room temperature for 3 days. The solution was then neutralized with $\mathrm{HCl}$ and extracted with ethyl acetate $(4 \times 50 \mathrm{ml})$. The organic layers were combined, dried $\left(\mathrm{MgSO}_{4}\right)$, evaporated and the residue applied to a Sephadex $\mathrm{LH}-20$ column $(1.5 \times 80 \mathrm{~cm})$, packed and eluted with chloroform-ethanol $(1: 1, \mathrm{v} / \mathrm{v})$. Fractions 38-66 were combined, evaporated, and freeze-dried to give a light-brown amorphous solid $(1.733 \mathrm{~g})$ having the same t.l.c. and spectral properties as (4) prepared from tannin. The two isomers observed previously were obtained in the same ratios as well.

1-(3,4-Dihydroxypheny)-3-(2,4,6-1rihydroxyphenyl)propan-2of (18) was prepared by reductions of $(4)$ or $(10)$ with Raney nickel. The compound to be reduced (1g) was combined with Raney nickel $(18)$ in dry ethanol $(5 \mathrm{ml})$ and the resulting suspension was stirred magnetically for $15 \mathrm{~min}$. It was then filtered and evaporated and the product purified on a Sephadex LH-20 column $(1.5 \times 80 \mathrm{~cm})$ using ethanol-water $(3: 1, \mathrm{v} / \mathrm{v})$ as a solvent. Evaporation of fractions $30-50$ gave an off-white amorphous solid (ca. $250 \mathrm{mg}$ ), $\boldsymbol{R}_{\mathrm{F}} \mathbf{0 . 7 9}$ and 0.61 on cellulose t.l.c. plates developed with solvents $B$ and $A$, red coloration with vanillin- $\mathrm{HCl}$ (Found: $\mathrm{C}, 59.2 ; \mathrm{H}, 5.9 . \mathrm{C}_{1}, \mathrm{H}_{16} \mathrm{O}_{6}-0.6 \mathrm{H}_{2} \mathrm{O}$ requires C, 59.4: H, 5.7\%): $\delta_{c} 31.6$ (C-3 propyl), 44.2 (C-1 propyl), 75.8 (C-2, propyl), 96.9 and 106.0 (C-3 and C-5, and C-1 phloroglucinol), 116.5, 118.0, 122.3, and 132.4 (C-2, C-5, C-6. and $C-1$, pyrocatechol), quaternaries at 144.6 and 146.1 (C-3 and $C-4$, pyrocatechol), and 158.2 and 158.7 p.p.m. (C-2. C-4, and C-6 phloroglucinol); $\delta 2.75(4 \mathrm{H}, \mathrm{m}, J 5.0,8.0,9.0,14.0 \mathrm{~Hz}$, propyl $1-\mathrm{H}$ and $3-\mathrm{H}), 4.05(1 \mathrm{H}, \mathrm{m}, \boldsymbol{\Omega}, 5,4.5,5.0,9.0 \mathrm{~Hz}$, propyl 2H), 5.95 (2 H, s, phloroglucinol ArH), and $6.7(3 \mathrm{H}, \mathrm{m}$, pyrocatechol ArH) [Found (for peracetate): C, 59.5; H, 4.95. $\mathrm{C}_{27} \mathrm{H}_{28} \mathrm{O}_{12}$ requires $\mathrm{C}, 59.56 ; \mathrm{H}, 5.15 \%$ ].

\section{References}

I P. Kiatgrajai, J. D. Wellons, L. Gollub, and J. D. White, J. Org. Chem. 1982, 47, 2910.

2 J. A. Kennedy, M. H. G. Munro, H. K. L. Powell, and L. Y. Foo, Aust. J. Chem, 1984, 37, 885.

3 L. Y. Foo and L. J. Porter, J. Chem. Soc. Perkin Trans. I, 1983, 1535.

4 K. D. Sears, R. L. Casebier, H. L. Herger, G. H. Slout. and L. E. McCandlish. J. Org. Chem, 1975, 33, 3244.

5 R. W. Hemingway and L. Y. Foo, J. Chem. Soc., Chem. Commun., 1983. 1035.

6 L. Y. Foo and R. W. Hemingway, J. Chem. Soc., Chem. Commun., 1984. 85.

7 F. W. Herrick, J. Agric. Food Chem., 1980, 22, 228.

8 J. J. Karchesy and R. W. Hemingway, J. Agric. Food Chem., 1980. 28, 222.

9 R. W. Hemingway, J. J. Karchesy, G. W. MCGraw, and R. A. Wielesek, Phytochemistry. 1983, 22 275.

10 R. W. Hemingway, L. Y. Foo, and L. J. Porter, J. Chem. Soc.jperk in
Trans. I. 1982, 1209.

11 Z. Czochanska, L. Y. Foo, R. H. Newman, and L. J. Porter. J. Chem. Sac. Perkin Trans I, 1980, 2278.

12 L. J. Porter, R. H. Newman, L. Y. Foo, H. Wong and R. W. Hemingway, J. Chem. Soc., Perkin Trans. I, 1982, 1217.

13 V. M. Williame, L. J. Porter, and R. W. Hemingway, Phytochemistry, 1983, 22, 569 .

14 M. R. Attwood, B. R. Brown, S. G. Lisseter, C. L. Torrero, and P. M. Weaver, J. Chem. Sac. Chem. Commun., 1984, 177.

IS D. Jacques and E. E. Hastam. J. Chem. Soc., Perkin Trans. I. 1974, 2663.

16 P. E. Laks and R. W. Hemingway, J. Chem. Soc., Perkin Trans. I, in the press.

17 D. G. Roux. D. Ferreire, H. K. L. Hundt, and E. Malan, J. Applied Polym. Sci., Polym. Symp. No. 22. 1975, 335.

18 G. W. McGraw, P. E. Laks, and R. W. Hemingway, J. Wood Chem. and Tecten.

19 R. W. Hemingway and G. W. McGraw, J. Wood Chem. and Techn.. 1982, 3, 421.

20 R. W. Hemingway and P. E. Laks, J. Chem. Soc. Chem. Commun., 1985, 746. 